УДК 005.05

DOI 10.31882/2311-4711.2019.25.5

\author{
Биятов Никита Валентинович \\ Магистрант программы Менеджмент-Управление проектами \\ Российский экономический университет имени Г.В.Плеханова, \\ Российская Федерация, г. Москва, 117997, Стремянный пер., 36 \\ E-mail:critman1@mail.ru,
}

\title{
ОЦЕНКА ЭФФЕКТИВНОСТИ ИТ-ПРОЕКТА С ПРИМЕНЕНИЕМ СRМ-ТЕХНОЛОГИЙ
}

Аннотация. В исследовании рассмотрены методы выбора информационных систем (на примере систем класса CRM - Customer Relationship Management). Изучены ключевые направления технологического развития CRM - технологий и предложены критерии выбора программных комплексов этого класса. Исследованы типичные проблемы и ошибки процесса выбора CRM - систем, а также теоретико - методологические подходы к оценке экономической эффективности их внедрения. Представлены этапы управления взаимоотношениями с клиентами, а также рассмотрены конкретные стратегии и тактики CRM и их внедрение. Статья выполнена под научным руководством д. ф.-м. н., профессора Тихонова С. В., РЭУ им. Г. В. Плеханова

Ключевые слова: системы управления взаимоотношениями с клиентами, критерии выбора CRM - систем, стратегия CRM.

Введение. В современном мире, взрывное развитие технологий дает возможность контролировать отношения между покупателем и продавцом, и вообще, способствует их кардинальному изменению. Новые достижения в технологии CRM предоставили такие методы для построения ориентированных на клиента стратегий, которые работают для новой структуры взаимоотношений с клиентами $[1,2]$. Вообще, CRM означает управление взаимоотношениями с клиентами, и ее применение значительно улучшает этот, старый как мир процесс, за счет использования специально разработанных программных приложений или технологических решений $[3,4]$.

Основная часть. Подготовка к новым стратегиям взаимоотношений с клиентами требует планирования и выполнения, прежде чем будут внедрены новые бизнес процессы и технологии. Эта подготовка снижает устойчивость к изменениям и сводит к минимуму влияние распространенных ошибок, связанных с новыми бизнес-процессами и технологиями. Рассмотрим основные идеи планирования и внедрения CRM, которые помогут ориентироваться в новых тенденциях продаж и маркетинга, ориентированных на клиента [5].

Истоки стратегии управления взаимоотношениями с клиентами. Потребность в управлении взаимоотношениями с клиентами выросла из изменений в модели покупатель-продавец. Этот переход к модели, ориентированной на клиента, начался в 1970-х годах. Специалисты по маркетингу усовершенствовали модель в 80-х годах, а в 90-х взрывной рост технологий продолжил новые решения. В 2000-х годах возможности интернета, достижения в области технологий социальных сетей и расширение возможностей потребителей изменили модель навсегда. Результатом стал сдвиг в отношении того, как обращаться с клиентами в качестве основного актива бизнеса. На сегодняшний день, стратегия управления взаимоотношениями с клиентами решать следующие задачи:

1. Управление удовлетворением потребностей клиентов, помимо разработки качественных продуктов и услуг.

2. Помощь в сохранении существующих клиентов, максимизация эффективности их использования и снижение стоимость приобретения новых [6].

3. Обеспечение удовлетворенности клиентов и узнаваемости бренда.

4. Улучшение общих отношений между бизнес-субъектом и целевой аудиторией налогоплательщиков [7].

Концентрация на индивидуальных потребностях конкретного клиентского сегмента требует другого набора значений отношений с клиентами. Удовлетворенность и лояльность клиентов стали теперь важными показателями бизнеса предоставление продуктов и услуг стало второстепенным по отношению к качеству обслуживания клиентов. Этот процесс протекает в условиях, когда передо- 
вое программное обеспечение снижает стоимость ведения бизнеса, но увеличивает ожидания в отношении качества и обслуживания.

Экономическая нестабильность в конце 20-го и начале 21-го веков ставила под сомнение существующие тенденции в сфере продаж и маркетинга, направленные на получение как можно большего числа новых клиентов и сделок. Максимизация ценности существующих клиентов и получение прибыли от этой стратегии помогли преодолеть экономические трудности этих десятилетий $[8,9]$.

Клиентоориентированные процессы лежат в основе современной бизнес-стратегии. Ведущие бизнес-игроки используют CRM-технологии и строят бизнес-процессы, которые связывают отношения с клиентами с положительными бизнес-результатами. Как никогда важно разработать CRM-стратегии, которые помогают, а не мешают планированию и внедрению CRM-технологий. Тщательная проработка стратегии фирмы служит основой для реализации поэтапной реорганизации взаимоотношений с клиентами. Необходимо четко представлять, цели и задачи, которые будут решаться с помощью внедряемых технологических решений, прежде чем приступать к планированию и внедрению CRM [10]. Необходимо принять эту методику действий, чтобы руководствоваться своей стратегией CRM и использовать технологии, которые укрепляют отношения с клиентами и обеспечивают положительные результаты для бизнеса [11].

Современная технология CRM позволяет компаниям собирать и хранить данные клиентов, полученные в результате взрыва цифровых медиа. Титаны технологий, такие как Amazon и Google, разработали технологию, которая позволяет отделам продаж и маркетинга определять сегменты клиентов и их уникальные потребности способами, ранее недоступными для небольших маркетинговых операций.

Идентификаторы мобильных устройств предоставляют важные метрики для мобильных рекламных решений. Сложная технология электронного маркетинга позволяет проводить тестирование и предоставляет сложные возможности проб и ошибок для информирования о решениях по маркетингу отношений $[12,13]$. Отделы продаж и маркетинга могут использовать данные CRM и анализировать тенденции клиентов, чтобы поддерживать непрерывность ценностного предложения CRM и общей стратегии, прежде чем связываться с клиентами напрямую. Необходимо проводить анализ данных о продажах, чтобы избежать внесения неправильных изменений тенденции роста. Такие плохо информированные корректировки могут включать эксперименты с неправильной сегментацией клиентов (сегментом с различными потребностями) ради роста [14]. Улучшение качества собираемых данных и рассмотрение процессов и технологий CRM, которые делают эти данные доступными на местах для операций продаж-вот цель рассматриваемых нам нововведений.

Заключение. Процессы, управляемые данными, важны для непрерывности общей стратегии CRM, поскольку они усиливают продажи и маркетинговую активность, раскрывая уникальные возможности и недостатки, а также помещают фирменный стиль компании под микроскоп измеримых результатов [15]. Частые изменения в стратегии означают, что стратегии нет. Управляемые данными процессы и технологии CRM помогают предотвратить подводные камни единообразных изменений. Преемственность стратегии не означает, что организация должна стоять на месте. Пока в предложении основной ценности есть стабильность, в способе его доставки могут и должны быть огромные инновации.

Таким образом, мы рассмотрели основные причины и этапы внедрения CRM. Ответили на вопросы, почему внедряется система CRM? Как выглядит успешная стратегия взаимоотношений с клиентами после ее реализации? Существуют бесчисленные модели управления изменениями, помогающие бороться с сопротивлением, страхом неудачи и плохой связью, которые мешают внедрению корпоративного программного обеспечения. Необходимо помнить, что стратегия, планирование и внедрение CRM зависит от отношений.

\section{Список использованных источников}

1. Анциборко К.В. Халиков М.А. Оптимальная структура производственного капитала компании // Вестник Российского экономического университета им. Г.В. Плеханова. 2007. № 5. С. 71-83.

2. Максимов Д.А. Методы и модели формирования оптимальной инвестиционной стратегии предприятия // Путеводитель предпринимателя. 2011. № 10. С. 157-166.

3. Максимов Д.А., Халиков М.А. Перспективы институционального подхода к оценке активов производственной корпорации // Актуальні проблеми економіки. 2016. Т. 183. № 9. С. 16-25.

4. Гордиенко М.С. Бюджетное стимулирование инновационного развития экономики России//Повышение управленческого, экономического, социального и инновационно-технического потенциала предприятий, отраслей и народно-хозяйственных комплексов сборник статей VII Международной научнопрактической конференции: сборник. Пенза, 2015. -С. 22-26. 
5. Зверева А.О. В коммерсанты б я пошел... Подготовка персонала для розничной торговли как фактор обеспечения конкурентоспособности предприятий отрасли//Российское предпринимательство. 2008. № 7-1. С. 102-107

6. Спиридонов Ю.Д. О необходимости комплексного подхода при исследовании рисков организации // Ученые записки Российской Академии предпринимательства. 2013. № 37. С. 285-296.

7. Сокольникова И.В. Оценка инвестиционных проектов в условиях значительной волатильности факторов внешней среды // Транспортное дело России. 2016. № 2. С. 91-94

8. Дюжов А.В. расчет размера налогового бремени по налогу на имущество образовательных учреждений // Бухгалтерский учет в бюджетных и некоммерческих организациях. 2009. № 2 (218). С. 5-10.

9. Новиков Д.А. Теория управления организационными системами-М.: МПСИ, 2015. - 584 с.

10. Пейн Э. Руководство по CRM. Путь к совершенствованию менеджмента клиентов. Издательство: Грев пабл, 2017. - 384 стр.

11. Юхимов Я.И., Юхимова Я.Я. Государственная поддержка - важнейшее условие сохранения потенциала горнорудной промышленности России в условиях мирового кризиса // Горный журнал. 2010. № 4. С. 37-39.

12. Дише Д. CRM Навигатор. Пособие по управлению взаимоотношениями с клиентами-М.: Издательство: Алексея Капусты,2016.-375 с.

13. Загородников С.Н., Максимов Д.А., Халиков М.А. Безопасность предпринимательской деятельности // Москва, 2010.

14. Караев А.К. Методологические особенности оценки эффективности научно-инновационных программ // Финансовая жизнь. - 2018. - №4. - С. 22-26.

15. Павлова Л.П., Понкратов В.В. Совершенствование НДПИ по нефти // Финансы. - 2008. - №6. - С. 37-40.

Biyatov Nikita Valentinovich

Student of Master Degree, Program Management Project Management,

Plekhanov Russian University of Economics

Russian Federation, 117997, Moscow, Stremyanny lane, 36

E-mail:critman1@mail.ru

\section{PERFORMANCE EVALUATION OF IT PROJECT WITH THE USE OF CRM TECHNOLOGIES}

Summary. The author considers information systems selection methods by the example of Customer Relationship Management systems CRM-systems. Key trends of technological development CRM - technologies are generalized in the paper and the specific criteria relating to CRM systems selection are described. The author researches common problems and mistakes of CRM -systems' selection process as well as theoretical and methodological approaches to the evaluation of their economic efficiency. The stages of customer relationship management and specific strategies are presented.

Keywords: customer relationship management systems, CRM system selection criteria, CRM strategy, economic efficiency of information systems. 